\title{
The effect of PLISSIT based counseling model on sexual function, quality of life, and sexual distress in women surviving breast cancer: a single-group pretest-posttest trial
}

\author{
Zohreh Keshavarz ${ }^{1}$, Elham Karimi ${ }^{2}$, Samira Golezar ${ }^{3^{*}}$,, Giti Ozgoli $^{1}$ and Maliheh Nasiri ${ }^{4}$
}

\begin{abstract}
Background: Diagnosis and treatment of breast cancer potentially leads to sexual dysfunction and sexual distress in women and negatively affects their quality of life (QoL). This study aimed at determining the effect of PLISSIT based counseling on sexual function, sexual distress, and QoL in women surviving breast cancer.
\end{abstract}

Methods: In this pre-test, post-test, single-group semi-experimental study, 65 women surviving breast cancer who were referred to the selected centers were included in the study via the available sampling method. Data gathering tools included a researcher-made demographic questionnaire, female sexual function index, beck depression inventory-II, State-Trait Anxiety Inventory, World Health Organization QoL-Brief, and Female Sexual Distress ScaleRevised. The counseling program (7 sessions 60 min each) was designed based on the PLISSIT model. The sexual function, sexual distress, and QoL were evaluated before, and 2 and 4 weeks after the intervention. To compare the mean scores of variables before and after the intervention, repeated-measured ANOVA was used.

Results: The findings showed that PLISSIT based counseling significantly reduced sexual distress and increased the scores of QoL and all its domains, as well as sexual function and all its domains in women surviving breast cancer $(p<0.05)$. There was no significant difference in the mean scores of variables 2 and 4 weeks after the intervention.

Conclusions: It seems that PLISSIT based counseling reduces sexual dysfunction and sexual distress and improves the QoL of women surviving breast cancer. So, it is recommended that these counseling programs be integrated into the health care program of this group of women.

Trial registration: TCTR202103170010, 17 March 2021, Retrospectively registered, at https://www.thaiclinicaltrials.org/.

Keywords: Counseling, PLISSIT model, Sexual dysfunction, Sexual distress, Quality of life, Breast cancer

\section{Background}

Breast cancer is the most common cancer around the world, with an estimated 1.7 million new cancer cases diagnosed in 2012 worldwide [1, 2]. Due to an increase

\footnotetext{
*Correspondence: golezar80@yahoo.com

${ }^{3}$ Department of Midwifery, Faculty of Nursing and Midwifery, Kermanshah University of Medical Sciences, Kermanshah, Iran Full list of author information is available at the end of the article
}

in life expectancy, urbanization, and following the Western lifestyle, breast cancer is rising in the developing countries [3]. With a prevalence of $18.24 \%$, breast cancer is the most common cancer among Iranian women [4]. Because of early diagnosis and the use of effective therapeutic methods, most women with breast cancer survive [5]. In patients with breast cancer, 5-year survival rates are reported as $70-85 \%$ worldwide [6]. Annually, 
approximately 10,000 cases of breast cancer are diagnosed in Iran with a five-year overall survival rate of $72 \%$ [7].

Breast cancer negatively affects the QoL and patients frequently report QoL concerns about physical, psychological, social, and spiritual issues [8-10]. Because of the importance of the breast in forming the female sexual identity, the reaction against this disease can include fear, anxiety, and depression [11]. Besides, breast cancer treatments may result in some sexual problems such as sexual dysfunction, sexual distress, and unsatisfactory body image due to the loss of a body part [12, 13]. In Iran, the prevalence of these sexual dysfunctions was reported as $84 \%$ in post-treatment [14] which is close to the global records [15]. Sexual dysfunction can negatively affect the QoL and interpersonal relationships $[15,16]$. Therefore, improving sexual function in these patients not only can enhance medical practice, but also can improve their well-being, QoL, and interpersonal relationships [17].

One of the most widely used interventions in the field of evaluating and managing sexual problems is the PLISSIT model. The model consists of four steps for addressing sexual concerns: Permission, Limited Information, Specific Suggestions, and Intensive Therapy [17, 18]. This model provides a framework for health care providers to implement appropriate and effective strategies to address sexual concerns $[19,20]$. Health care providers have an important role in educating and providing psychological support to breast cancer patients and their families [21].

Since the survival rate of women with breast cancer is increasing due to advances in diagnostic and therapeutic methods, it is necessary to take measures to control the complications of the disease and improve their QoL [10, 21]. Considering the scarcity of research on the application of the PLISSIT model concerning sexual function, sexual distress, and QoL of breast cancer patients, the present study was conducted to determine the effect of PLISSIT- based counseling model on sexual function, QoL, and sexual distress in women surviving breast cancer.

\section{Methods}

The present study was performed as a single group pretest-posttest semi-experimental design.

\section{Participant recruitment}

The sample population was women surviving breast cancer referred to the gynecological clinics of selected centers in Tehran, Iran (Bu Ali and Mehr Hospital), from April to October 2017 who met the inclusion criteria. The sample size was 59 estimated following similar research [18] and using the following formula.

$$
n \geq 2 \frac{\left(z_{\alpha / 2}+z_{\beta}\right)^{2} \sigma^{2}}{\left(\mu_{1}-\mu_{2}\right)^{2}}(1-\rho)
$$

Subjects were selected using the available sampling method. Finally, 67 women entered the study, and 65 of them completed the study (Fig. 1).

\section{Inclusion criteria}

literacy, being married, absence of chronic psychological and physical diseases, not having taken Tamoxifen for at least three years, having a history of mastectomy, having at least one sexual dysfunction (scores lower than 28 in FSFI questionnaire).

\section{Exclusion criteria}

Gynecological tumor such as vaginal, cervical, and uterine cancer, a history of pelvic injury that prevents sexual intercourse, alcohol or substance abuse, and the existence of sores or any lesions in the genitalia, having depression (scores higher than 13 in Beck Depression Inventory-II), and having anxiety (scores higher than 42 in State-Trait Anxiety Inventory).

\section{Study tools}

Data gathering tools included a researcher-made demographic questionnaire, FSFI, BDI-II, STAI, WHOQOLBREF, and FSDS-R.

1. The researcher-made demographic questionnaire consisted of 7 questions designed according to the purpose of the study including age, duration of the marriage, woman and her husband's education, woman and her husband's occupation, and the number of children. the demographic questionnaire developed for this study is provided as Additional file 1.

2. The FSFI questionnaire included 19 questions that evaluate the female sexual function in 6 domains including sexual desire, arousal, lubrication, orgasm, satisfaction, and pain. The total score is the sum of the scores in all domains [22]. All items are rated on a 5 -point Likert scale (1-5), The maximum score is 36 , and scores lower than 28 indicate an undesirable sexual function [19]. The validity and reliability of this scale have been confirmed in several studies in Iran [23-25].

3. The BDI-II included 21 items aimed at diagnosing and measuring the severity of depression. All items are rated on a 4-point Likert scale (0-3). A score of 0-13 shows minor depression, a score of 14-19 indicates mild depression, a score of 20-28 represents moderate depression, and a score of 29-63 is a sign 

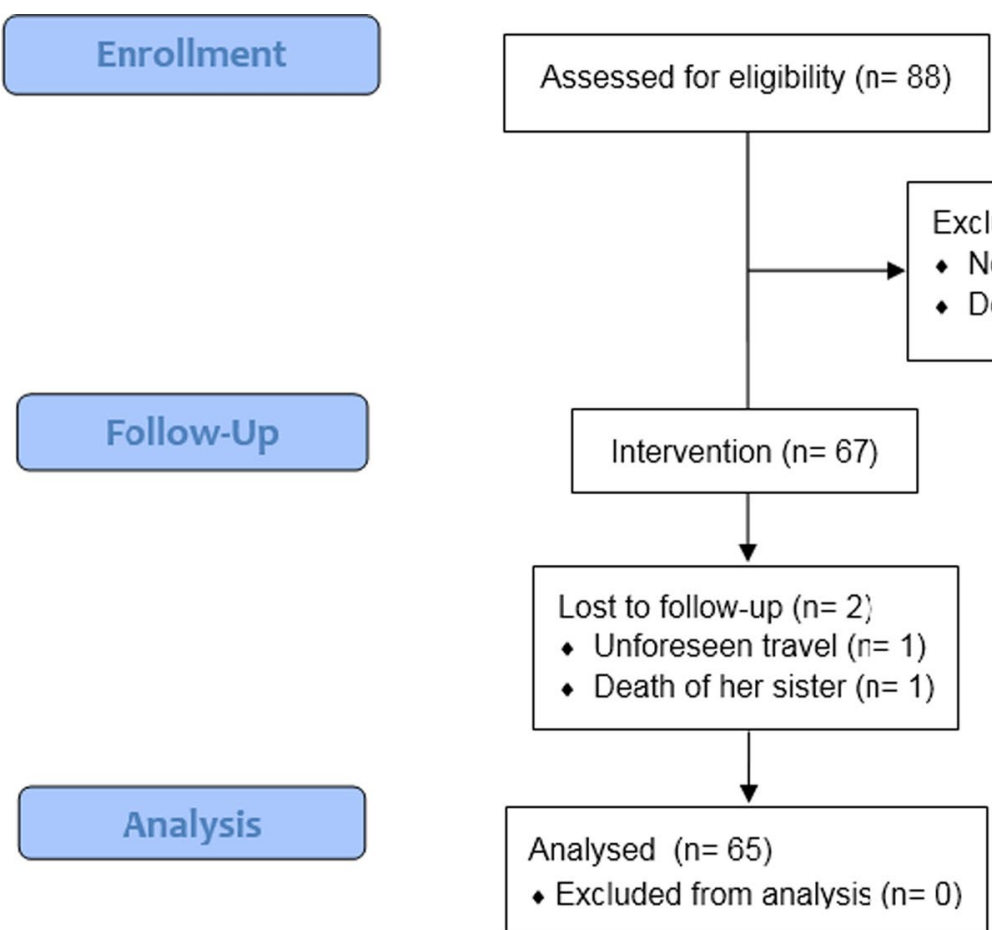

Fig. 1 The study flowchart

of severe depression [26]. The validity and reliability of this scale have also been confirmed in Iran [27].

4. The STAI is a psychological inventory that includes 40 items. Both state and trait anxiety levels are measured by this scale. They score on a 4-point Likert scale (1-4), in which higher scores show greater levels of anxiety symptoms [28]. The cut-off point on the state and trait anxiety scale is 43 and above, indicating moderate to high anxiety [29]. The validity and reliability of this scale have been confirmed in Iran $[29,30]$

5. The WHOQOL-Bref questionnaire includes 26 questions that measure the QoL. This questionnaire has 4 domains i.e. physical health (7 questions), psychological (6 questions), social relationships (3 questions), and environment (with 8 questions). Also, this questionnaire has two other questions that assess general health and overall QoL. All items are rated on a 5 -point Likert scale (1-5); first, a raw score is calculated for each domain which is then converted to a standard score ranging between 0 and 100. A higher score is indicative of a higher level of QoL [31]. Likewise, The reliability and validity of this questionnaire have been confirmed in Iran [32].

6. The FSDS-R questionnaire included 12 items that assess sexual distress associated with sexual activities. Each item is rated on a 5-point Likert scale
(0-4). A higher score indicates greater sexual distress [33]. Like the previous questionnaires, the validity and reliability of this scale have been confirmed in Iran [34].

\section{Data collection}

After obtaining permission from the ethics committee, the researcher (E.K) invited all the women surviving breast cancer referred to the selected centers and explained the purpose of the study and the frequency of counseling sessions to them. They were also reassured about the confidentiality of their information.

At first, the demographic, FSFI, STAI, and BDI-II questionnaires were completed by all participants and if eligible, they entered the study. After obtaining informed written consent, the consultation schedules were arranged with them. Then, the selected women answered the questionnaires of WHOQOL-BREF, FSDS-R, and FSFI in the pretest stage. In all samples, the sexual function, sexual distress, and QoL were again evaluated 2 and 4 weeks after intervention (posttest stage). The intervention included a PLISSIT-based consultation model for sexual treatment. 7 counseling sessions were conducted lasting $60 \mathrm{~min}$ for 4 weeks. All sessions were conducted individually in the counseling room in the selected centers. PLESSIS-based intervention is as follows: 
1. Permission: researcher talked about breast cancer and sexuality during the first and second sessions. In this stage, the researcher used her counseling skills, especially listening skills and attention to nonverbal gestures, and a therapeutic rapport was established (Developing Rapport). The researcher first asked some open-ended questions about sexual function. For example, 'what was your sexual experience when you were diagnosed with breast cancer?. During the client's conversation, the researcher noticed her misconceptions, lack of information, and concerns, and by taking a sexual history and clinical examination, the client's sexual problem was finally identified.

2. Limited knowledge: During the third and fourth sessions, the researcher provided participants with brief information about the effects of breast cancer and its treatments on sexual function. At this stage, the researcher focused on correcting misconceptions such as 'intercourse makes my symptoms worse'. Also, brief descriptions were given of the anatomy and physiology of the reproductive system, the sexual response cycle, and the individual's sexual problem. In this regard, 10 color images were used as auxiliary tools.

3. Specific suggestion: During the fifth and sixth sessions, the researcher used a problem-solving approach to address issues that the patient had personally experienced. For example, if a woman expressed concern about sexual intercourse with her husband for fear of pain and discomfort, the researcher recommended the use of relaxation strategies and appropriate medications (prescribed by a doctor).

4. Intensive therapy: In the seventh session, more complex cases of sexual dysfunction were referred to specialists (such as a sex therapist, psychologist, and specialist physician) for diagnosis and treatment. This stage was necessary for patients with severe or long-term sexual problems to receive an intensive and more specific treatment.

\section{Statistical analysis}

All data were analyzed by the SPSS software version 22 . The normal distribution of all continuous variables was investigated using the Kolmogorov-Smirnov test. For comparison between means of three related groups (before, and 2 and 4 weeks after intervention), repeatedmeasured (RM) ANOVA was used. When significant interactions were identified in the ANOVA test, the Bonferroni correction was used for post hoc comparisons. A $p$-value of 0.05 was considered significant.

\section{Results}

65 women surviving breast cancer, with a mean age of $43.4 \pm 5.6$ years participated in this study. The majority of these women were 30-40 years of age. The mean duration of marriage was $12.8 \pm 3.9$ years. The majority of the participants had a university degree and $58.49 \%$ were employed. The demographic characteristics of the participants are presented in Table 1.

According to the results, the mean scores of total sexual function and QoL increased after the intervention. Also, the mean score of sexual distress decreased after the intervention and all these changes were statistically significant $(p<0.001)$. Table 2 shows the changes in sexual distress, total sexual function, and QoL at the three measurement points. The findings of the Bonferroni post hoc test showed a statistically significant difference for each of these variables before and after the intervention $(p<0.001)$. However, there was no significant difference between the mean scores of variables 2 weeks and 4 weeks after the intervention $(p>0.05)$.

Also, the results of RM-ANOVA showed that the scores of different dimensions of sexual function and QoL after counseling increased significantly $(p<0.001)$, which are shown in Tables 3 and 4, respectively. Pairwise

Table 1 Demographic characteristics of the participants $(n=65)$

\begin{tabular}{|c|c|c|c|}
\hline Variable & Level & Number & Percentage \\
\hline \multirow[t]{4}{*}{ Age (years) } & $20-30$ & 19 & $29 / 23$ \\
\hline & $31-40$ & 24 & 36.92 \\
\hline & $41-50$ & 16 & 24.62 \\
\hline & $51-60$ & 6 & 9.23 \\
\hline \multirow[t]{4}{*}{ Marriage duration (years) } & $5>$ & 9 & 13.85 \\
\hline & $5-10$ & 12 & 18.46 \\
\hline & $10-15$ & 23 & 35.38 \\
\hline & $15-25$ & 21 & 32.31 \\
\hline \multirow[t]{3}{*}{ Education level } & Under diploma & 5 & 7.7 \\
\hline & Diploma & 20 & 30.77 \\
\hline & University degree & 40 & 61.53 \\
\hline \multirow[t]{2}{*}{ Employment status } & Housewife & 27 & 41.54 \\
\hline & Employee & 38 & 58.46 \\
\hline \multirow[t]{3}{*}{ Husband education } & Under diploma & 7 & 10.76 \\
\hline & Diploma & 15 & 23.07 \\
\hline & University degree & 43 & 66.15 \\
\hline \multirow{4}{*}{$\begin{array}{l}\text { Husband employment } \\
\text { status }\end{array}$} & Employed & 28 & 43.08 \\
\hline & Self-employed & 26 & 40 \\
\hline & Worker & 6 & 9.23 \\
\hline & Unemployed & 5 & 7.7 \\
\hline \multirow[t]{4}{*}{ Number of children } & None & 16 & 24.61 \\
\hline & $1-2$ & 23 & 35.38 \\
\hline & $3-4$ & 21 & 32.30 \\
\hline & $5 \leq$ & 5 & 7.7 \\
\hline
\end{tabular}


Table 2 Changes of sexual distress, total sexual function, and QoL over time among women who received PLISSIT-based intervention $(n=65)$

\begin{tabular}{|c|c|c|c|c|c|c|}
\hline \multirow[t]{2}{*}{ Variable } & \multirow{2}{*}{$\begin{array}{l}\text { Before intervention } \\
\text { (T1) } \\
\text { Mean (SD) }\end{array}$} & \multirow{2}{*}{$\begin{array}{l}2 \text { weeks after } \\
\text { intervention (T2) } \\
\text { Mean (SD) }\end{array}$} & $\begin{array}{l}4 \text { weeks after } \\
\text { intervention (T3) }\end{array}$ & \multirow[t]{2}{*}{$F$} & \multirow[t]{2}{*}{$p$-value* } & \multirow{2}{*}{$\begin{array}{l}p \text {-value** } \\
\text { (pairwise } \\
\text { comparison) }\end{array}$} \\
\hline & & & Mean (SD) & & & \\
\hline Sexual function & $23.33(2.72)$ & $31.66(3.77)$ & $31.44(3.88)$ & 11.8 & 0.001 & $\begin{array}{l}\mathrm{T} 1<\mathrm{T} 2(p=0.001) \\
\mathrm{T} 1<\mathrm{T} 3(p=0.001)\end{array}$ \\
\hline Sexual distress & $24.34(4.21)$ & $21.74(4.16)$ & $21.52(4.08)$ & 9.92 & 0.001 & $\begin{array}{l}\mathrm{T} 1>\mathrm{T} 2(p=0.003) \\
\mathrm{T} 1>\mathrm{T} 3(p=0.001)\end{array}$ \\
\hline QoL & $51.63(4.14)$ & $58.35(8.23)$ & $58.91(7.25)$ & 15.6 & 0.001 & $\begin{array}{l}\mathrm{T} 1<\mathrm{T} 2(p=0.001) \\
\mathrm{T} 1<\mathrm{T} 3(p=0.001)\end{array}$ \\
\hline
\end{tabular}

* Repeated measure ANOVA test

${ }^{*}$ Bonferroni posthoc test

Table 3 Changes of main domains of sexual function over time among women who received PLISSIT-based intervention ( $\mathrm{n}=65$ )

\begin{tabular}{|c|c|c|c|c|c|c|}
\hline \multirow[t]{2}{*}{ Variable } & \multirow{2}{*}{$\begin{array}{l}\text { Before intervention } \\
\text { (T1) } \\
\text { Mean (SD) }\end{array}$} & \multirow{2}{*}{$\begin{array}{l}2 \text { weeks after } \\
\text { intervention (T2) } \\
\text { Mean (SD) }\end{array}$} & $\begin{array}{l}4 \text { weeks after } \\
\text { intervention (T3) }\end{array}$ & \multirow[t]{2}{*}{$\mathrm{F}$} & \multirow[t]{2}{*}{$p$-value* } & \multirow{2}{*}{$\begin{array}{l}p \text {-value** } \\
\text { (pairwise } \\
\text { comparison) }\end{array}$} \\
\hline & & & Mean (SD) & & & \\
\hline Desire & $3.12(0.92)$ & $3.97(1.01)$ & $4.15(1.43)$ & 15.25 & 0.001 & $\begin{array}{l}\mathrm{T} 1<\mathrm{T} 2(p=0.001) \\
\mathrm{T} 1<\mathrm{T} 3(p=0.001)\end{array}$ \\
\hline Arousal & $5.57(1.95)$ & 7.54 (2.29) & $6.86(2.35)$ & 13.13 & 0.001 & $\begin{array}{l}\mathrm{T} 1<\mathrm{T} 2(p=0.001) \\
\mathrm{T} 1<\mathrm{T} 3(p=0.001)\end{array}$ \\
\hline Lubrication & $4.41(0.93)$ & $5.66(1.62)$ & $5.69(2.33)$ & 10.99 & 0.001 & $\begin{array}{l}\mathrm{T} 1<\mathrm{T} 2(p=0.001) \\
\mathrm{T} 1<\mathrm{T} 3(p=0.001)\end{array}$ \\
\hline Orgasm & $3.67(1.10)$ & $5.06(1.57)$ & $5.29(1.86)$ & 18.93 & 0.001 & $\begin{array}{l}\mathrm{T} 1<\mathrm{T} 2(p=0.001) \\
\mathrm{T} 1<\mathrm{T} 3(p=0.001)\end{array}$ \\
\hline Satisfaction & $3.36(1.45)$ & $4.91(1.43)$ & $5.09(1.53)$ & 28.10 & 0.001 & $\begin{array}{l}\mathrm{T} 1<\mathrm{T} 2(p=0.001) \\
\mathrm{T} 1<\mathrm{T} 3(p=0.001)\end{array}$ \\
\hline Pain & $3.18(1.23)$ & $4.52(1.65)$ & $4.35(1.96)$ & 12.15 & 0.001 & $\begin{array}{l}\mathrm{T} 1<\mathrm{T} 2(p=0.001) \\
\mathrm{T} 1<\mathrm{T} 3(p=0.001)\end{array}$ \\
\hline
\end{tabular}

* Repeated Measure ANOVA test

${ }^{* *}$ Bonferroni post-hoc test

Table 4 Changes of main domains of QoL over time among women who received PLISSIT-based intervention $(n=65)$

\begin{tabular}{|c|c|c|c|c|c|c|}
\hline \multirow[t]{2}{*}{ Variable } & \multirow{2}{*}{$\begin{array}{l}\text { Before intervention } \\
\text { (T1) } \\
\text { Mean (SD) }\end{array}$} & \multirow{2}{*}{$\begin{array}{l}2 \text { weeks after } \\
\text { intervention (T2) } \\
\text { Mean (SD) }\end{array}$} & $\begin{array}{l}4 \text { weeks after } \\
\text { intervention (T3) }\end{array}$ & \multirow[t]{2}{*}{$F$} & \multirow[t]{2}{*}{$p$-value } & \multirow{2}{*}{$\begin{array}{l}p \text {-value }{ }^{* *} \\
\text { (pairwise } \\
\text { comparison) }\end{array}$} \\
\hline & & & Mean (SD) & & & \\
\hline Physical health & $13.88(1.71)$ & $15.15(1.84)$ & $15.31(1.88)$ & 18.37 & 0.001 & $\begin{array}{l}\mathrm{T} 1<\mathrm{T} 2(p=0.001) \\
\mathrm{T} 1<\mathrm{T} 3(p=0.001)\end{array}$ \\
\hline Psychological & $12.08(2.14)$ & $13.75(3.98)$ & $13.91(2.65)$ & 11.36 & 0.001 & $\begin{array}{l}\mathrm{T} 1<\mathrm{T} 2(p=0.001) \\
\mathrm{T} 1<\mathrm{T} 3(p=0.001)\end{array}$ \\
\hline Relationships & $6.29(1.07)$ & $7.20(1.91)$ & $7.31(1.95)$ & 10.10 & 0.001 & $\begin{array}{l}\mathrm{T} 1<\mathrm{T} 2(p=0.001) \\
\mathrm{T} 1<\mathrm{T} 3(p=0.001)\end{array}$ \\
\hline Environment & $15.74(2.04)$ & $17.94(2.69)$ & $17.69(2.96)$ & 21.37 & 0.001 & $\begin{array}{l}\mathrm{T} 1<\mathrm{T} 2(p=0.001) \\
\mathrm{T} 1<\mathrm{T} 3(p=0.001)\end{array}$ \\
\hline
\end{tabular}

\footnotetext{
${ }^{*}$ Repeated Measure ANOVA test
}

** Bonferroni posthoc test

comparison by Bonferroni post hoc test showed significant differences between the mean scores of variables before and after the intervention for all domains of QoL and sexual function $(p<0.001)$, but there was no 
significant difference between the mean scores of variables 2 and 4 weeks after the intervention $(p>0.05)$.

\section{Discussion}

The present study was a quasi-experimental pre-test and post-test one-group study that aimed to determine the effect of the PLISSIT-based consultation model on sexual function and sexual distress and QoL of 65 women surviving breast cancer.

In the current study the mean age of participants was $43.4 \pm 5.6$ years which matched the mean age of participants of Saboula and Shahin [18], and Faghani and Ghaffari [35] studies, i.e., $43.1 \pm 10.0$ years and $43.2 \pm 4.6$ years respectively. Also, $60 \%$ of women in the present study were below 40 years of age that is similar to other studies $[15,18,36]$. The age distribution of breast cancer in Iranian women is about one decade lower than other countries, which indicates more psychological and sexual problems compared to others [36].

The results showed that PLISSIT-based counseling significantly reduced sexual distress and increased the scores of QoL and all its domains, and sexual function and all its domains in women with breast cancer. However, there was no significant difference in the mean scores of variables between 2 and 4 weeks after the intervention, which indicates the reliability of the intervention.

Consistent with our study, Faghani and Ghaffari showed improved quality of sexual life and sexual function and its all aspects in post-mastectomy women four weeks after the PLISSIT- based consultation presented in four 90-min sessions [35]. Esmkhani et al., reported similar effects on improving all domains of QoL of women with breast cancer 6 , and 12 weeks after application of PLISSIT model [36]. Also, Saboula and Shahin showed that the application of the PLISSIT model was effective in enhancing body image, couple satisfaction, and all sexual function index domains except for the domain of desire for women with breast cancer three weeks after receiving six $2 \mathrm{~h}$ counseling sessions [18]. The influence of various factors such as fatigue, stress, depression, and couple relationships on sexual desire can justify this difference with our study [37]. Other studies have found similar results on the effect of PLISSIT-based counseling on improving sexual function, sexual distress, and marital intimacy in women with gynecological cancers [38, 39]. Contrary to these results, in a study by Khoei et al., consultation using the PLISSIT model had no significant effect on sexual behavior of women with breast cancer compared to the control group at six weeks and 12 weeks after intervention [15]. This difference may be due to varying approaches to implementing interventions, the number of sessions, tools, and characteristics of the study population.

One of the limitations of our study was the absence of the participants' husbands. Second, due to the limited access to samples, it was not possible to conduct a clinical trial with the control group. Third, the participants were selected from large urban areas, which might hamper generalizability of the results.

\section{Conclusion}

In general, the increasing prevalence of breast cancer in recent years and its negative effects on the physical, psychological and social aspects of women's lives has led to its being recognized as a major women health problem that has a negative effect on their QoL through reducing sexual function and distress $[15,16]$. Besides, there is a lack of adequate related education, so, educating women surviving breast cancer on changes in sexual function following cancer through intervention programs such as PLISSIT based counseling can help them cope with the disease and thus improve these women's QoL as an important member of the family. Therefore, due to the simplicity and applicability of the PLISSIT model, it is recommended that it be integrated into the health care program (e.g. sexual health counseling and training programs) of this group of patients by health care providers such as midwives.

\section{Abbreviations}

PLISSIT: Permission, Limited Information, Specific Suggestion and Intensive Therapy; QoL: Quality of life; RM-ANOVA: Repeated measured analysis of variance; FSFI: Female sexual function index; BDI-II: Beck depression inventory-II; STAI: State-Trait Anxiety Inventory; WHOQOL-BREF: World Health Organization Quality of Life Questionnaire-Brief; FSDS-R: Female Sexual Distress Scale-Revised.

\section{Supplementary Information}

The online version contains supplementary material available at https://doi. org/10.1186/s12905-021-01570-4.

Additional file 1. The researcher-made demographic questionnaire. This questionnaire consists of 7 items about the demographic characteristics of the participants.

\section{Acknowledgements}

The authors would like to thank all the women who participated in this study.

\section{Authors' contributions}

ZK participated in the design of the study, data analysis, and supervised the research; EK participated in design of the study, data collection and analysis; SG participated in analysis and interpretation of data, and provided an initial draft of the manuscript and is the current corresponding author; MN and GO participated in the design of the study and data analysis. All authors read and approved the final manuscript.

\section{Funding}

No funding received. 


\section{Availability of data and materials}

The datasets used and/or analysed during the current study are available from the corresponding author on reasonable request. All supporting data are available through the corresponding author.

\section{Declarations}

\section{Ethics approval and consent to participate}

This study was approved by the Ethics Committee of the School of Nursing and Midwifery, Shahid Beheshti University of Medical Sciences, Tehran, Iran (IR. SBMU.PHNM.1395.404). Also, the written informed consent was obtained from all individual participants included in the study.

\section{Consent for publication}

Not applicable.

\section{Competing interests}

Authors declare that they have no competing interests.

\begin{abstract}
Author details
${ }^{1}$ Department of Midwifery and Reproductive Health, School of Nursing and Midwifery, Shahid Beheshti University of Medical Sciences, Tehran, Iran. ${ }^{2}$ Student Research Committee, School of Nursing and Midwifery, Shahid Beheshti University of Medical Sciences, Tehran, Iran. ${ }^{3}$ Department of Midwifery, Faculty of Nursing and Midwifery, Kermanshah University of Medical Sciences, Kermanshah, Iran. ${ }^{4}$ Department of Basic Sciences, School of Nursing and Midwifery, Shahid Beheshti University of Medical Sciences, Tehran, Iran.
\end{abstract}

Received: 9 January 2021 Accepted: 13 December 2021 Published online: 16 December 2021

\section{References}

1. Colombage UN, Lin KY, Soh SE, Frawley HC. Prevalence and impact of bladder and bowel disorders in women with breast cancer: a systematic review with meta-analysis. Neurourol Urodyn. 2020. https://doi.org/10. 1002/nau.24531.

2. Triberti S, Savioni L, Sebri V, Pravettoni G. eHealth for improving quality of life in breast cancer patients: a systematic review. Cancer Treat Rev. 2019. https://doi.org/10.1016/j.ctrv.2019.01.003.

3. World Health Organization. Breast cancer: prevention and control. 2017. http://www.who.int/cancer/detection/breastcancer/en/index1.html. Accessed 9 Oct 2017.

4. Amori N, Aghajani M, Asgarian F, Jazayeri M. Epidemiology and trend of common cancers in Iran (2004-2008). Eur J Cancer Care. 2017. https://doi. org/10.1111/ecc.12449.

5. Matsuda A, Yamaoka K, Tango T, Matsuda T, Nishimoto H. Effectiveness of psychoeducational support on quality of life in early-stage breast cancer patients: a systematic review and meta-analysis of randomized controlled trials. Qual Life Res. 2014. https://doi.org/10.1007/s11136-013-0460-3.

6. Zaidi Z, Dib HA. The worldwide female breast cancer incidence and survival, 2018. Cancer Res. 2019. https://doi.org/10.1158/1538-7445. AM2019-4191.

7. Nafissi N, Khayamzadeh M, Zeinali Z, Pazooki D, Hosseini M, Akbari ME. Epidemiology and histopathology of breast cancer in Iran versus other Middle Eastern countries. Middle East J Cancer. 2018. https://doi.org/10. 30476/mejc.2018.42130.

8. Mehrabi E, Hajian S, Simbar M, Hoshyari M, Zayeri F. The lived experience of Iranian women confronting breast cancer diagnosis. J Caring Sci. 2016. https://doi.org/10.15171/jcs.2016.005.

9. Casellas-Grau A, Font A, Vives JJPO. Positive psychology interventions in breast cancer. A systematic review. JPO. 2014;23(1):9-19.

10. Uzun Ö, Aslan FE, Selimen D, Koç M. Quality of life in women with breast cancer in Turkey. J Nurs Scholarsh. 2004. https://doi.org/10.1111/j.15475069.2004.04039.x.

11. Taira N, Shimozuma K, Shiroiwa T, Ohsumi S, Kuroi K, Saji S, et al. Associations among baseline variables, treatment-related factors and health-related quality of life 2 years after breast cancer surgery. Breast Cancer Res Treat. 2011. https://doi.org/10.1007/s10549-011-1631-y.

12. Ghaemi SZ, Keshavarz Z, Tahmasebi S, Akrami M, Heydari ST. Conflicts women with breast cancer face with: a qualitative study. J Fam Med Prim Care. 2019. https://doi.org/10.4103/jfmpc.jfmpc_272_18.

13. Raggio GA, Butryn ML, Arigo D, Mikorski R, Palmer SC. Prevalence and correlates of sexual morbidity in long-term breast cancer survivors. Psychol Health. 2014. https://doi.org/10.1080/08870446.2013.879136.

14. Harirchi I, Montazeri A, Bidokhti FZ, Mamishi N, Zendehdel K. Sexual function in breast cancer patients: a prospective study from Iran. J Exp Clin Cancer Res. 2012. https://doi.org/10.1186/1756-9966-31-20.

15. Khoei EM, Kharaghani R, Shakibazadeh E, Faghihzadeh S, Aghajani N, Korte JE, et al. Sexual health outcomes of PLISSIT-based counseling versus grouped sexuality education among Iranian women with breast cancer: a randomized clinical trial. Sex Relatsh Ther. 2020. https://doi.org/10.1080/ 14681994.2020 .1732910$.

16. Zeighami Mohammadi S, Ghaffari F. Sexual dysfunction and its correlation with quality of life among women affected with cancer. Iran J Obstet Gynecol Infertil. 2009;12(2):39-46.

17. Boa R. Female sexual dysfunction. S Afr Med J. 2014. https://doi.org/10. 7196/samj.8373.

18. NeS Saboula, Shahin MA. Effectiveness of application of PLISSIT counseling model on sexuality for breast cancer's women undergoing treatment. Am J Nurs Sci. 2015. https://doi.org/10.11648/j.ajns.20150404.21.

19. Tork Zahrani S, Azad M, Ozgoli G, Banaei M, Mahmoudikohani F. The effectiveness of consultation based on plissit model on sexual function of lactating women. Nurs Midwifery J. 2016;14(7):639-47.

20. Almeida NGD, Britto DF, Figueiredo JV, Moreira TMM, Carvalho REFLD, Fialho AVDM. PLISSIT model: sexual counseling for breast cancer survivors. Rev Bras Enferm. 2019. https://doi.org/10.1590/ 0034-7167-2018-0525.

21. Aghabarari M, Ahmadi F, Mohammadi E, Hagizadeh E, Varvarani Farahani A. Physical, emotional and social dimension of quality of life among breast cancer women under chemotherapy. Iran J Nurs Res. 2007;1(3):55-65.

22. Rosen R, Brown C, Heiman J, Leiblum S, Meston C, Shabsigh R, et al. The Female Sexual Function Index (FSFI): a multidimensional self-report instrument for the assessment of female sexual function. J Sex Marital Ther. 2000. https://doi.org/10.1080/009262300278597.

23. Mohammadi $\mathrm{KH}$, Heydari M, Faghihzadeh S. The female sexual function index (FSFI): validation of the Iranian version. Payesh. 2008;7(3):269-78.

24. Ghassamia M, Asghari A, Shaeiri MR, Safarinejad MR. Validation of psychometric properties of the Persian version of the Female Sexual Function Index. Urol J. 2013;10(2):878-85.

25. Fakhri A, Pakpour AH, Burri A, Morshedi H, Zeidi IM. The Female Sexual Function Index: translation and validation of an Iranian version. J Sex Med. 2012. https://doi.org/10.1111/j.1743-6109.2011.02553.x.

26. Steer RA, Rissmiller DJ, Beck AT. Use of the Beck Depression Inventory-\|I with depressed geriatric inpatients. Behav Res Ther. 2000. https://doi.org/ 10.1016/s0005-7967(99)00068-6.

27. Stefan-Dabson K, Mohammadkhani P, Massah-Choulabi O. Psychometrics characteristic of Beck Depression Inventory-II in patients with magor depressive disorder. J Rehabil. 2007:8:82-6.

28. Spielberger CD. State-Trait anxiety inventory. Corsini Encycl Psychol. 2010. https://doi.org/10.1002/9780470479216.corpsy0943.

29. Azizi M, Momeni K. The effectiveness of cognitive group therapy on reducing depression and anxiety in the Kermanshah older women. J Clin Res Paramed Sci. 2014;3(3):178-87.

30. Mahram B. Standardization speilberger state-trait anxiety inventory in Mashad city (Iran). Tehran: Allame Tabatabayee University; 1993.

31. WHOQOL. Development of the World Health Organization WHOQOLBREF quality of life assessment. Psychol Med. 1998. https://doi.org/10. 1017/S0033291798006667.

32. Nejat S, Montazeri A, Holakouie Naieni K, Mohammad K, Majdzadeh SR. The World Health Organization quality of Life (WHOQOL-BREF) questionnaire: translation and validation study of the Iranian version. J School Public Health Inst Public Health Res. 2006;4(4):1-12.

33. Derogatis L, Clayton A, Lewis-D'agostino D, Wunderlich G, Fu Y. Validation of the female sexual distress scale-revised for assessing distress in women with hypoactive sexual desire disorder. J Sex Med. 2008. https://doi.org/ 10.1111/j.1743-6109.2007.00672.x 
34. Ghassami M, Asghari A, Shaeeri MR, Soltaninejad Z, Safarinejad MR. Psychometric properties of the Female Sexual Distress Scale-Revised among a sample of non-clinical Iranian women. Int J Psychiatry Clin Pract. 2014. https://doi.org/10.3109/13651501.2014.940048.

35. Faghani S, Ghaffari F. Effects of sexual rehabilitation using the PLISSIT model on quality of sexual life and sexual functioning in post-mastectomy breast cancer survivors. Asian Pac J Cancer Prev. 2016. https://doi. org/10.22034/APJCP.2016.17.11.4845.

36. Esmkhani M, Kharaghani R, Shakibazadeh E, Faghihzadeh S, Korte JE, Merghati-Khoei E. Comparison of the effects of the PLISSIT model versus the sexual health model on quality of life among women with breast cancer. Sex Disabil. 2021. https://doi.org/10.1007/s11195-020-09661-0.

37. Golbabaei F, Jamshidimanesh M, Ranjbar H, Azin SA, Moradi S. Efficacy of sexual counseling based on PLISSIT model on sexual functioning in women with polycystic ovarian syndrome. J Mazandaran Univ Med Sci. 2019;29(172):43-52

38. Chun N. Effectiveness of PLISSIT model sexual program on female sexual function for women with gynecologic cancer. J Korean Acad Nurs. 2011. https://doi.org/10.4040/jkan.2011.41.4.471.

39. Nho J-H. Effect of PLISSIT model sexual health enhancement program for women with gynecologic cancer and their husbands. J Korean Acad Nurs. 2013. https://doi.org/10.4040/jkan.2013.43.5.681.

\section{Publisher's Note}

Springer Nature remains neutral with regard to jurisdictional claims in published maps and institutional affiliations.

- fast, convenient online submission

- thorough peer review by experienced researchers in your field

- rapid publication on acceptance

- support for research data, including large and complex data types

- gold Open Access which fosters wider collaboration and increased citations

- maximum visibility for your research: over $100 \mathrm{M}$ website views per year

At BMC, research is always in progress.

Learn more biomedcentral.com/submissions 